IOSR Journal of Pharmacy

ISSN: 2250-3013, www.iosrphr.org

||| Volume 2 Issue 5 ||| Sep-Oct. 2012 || || PP.47-56

\title{
Cinnarizine loaded lipid based system: preparation, optimization and in-vitro evaluation
}

\author{
Shubham Rai ${ }^{1}$, Mohd Yasir* ${ }^{1}$ \\ ${ }^{1}$ Department of Pharmaceutics, ITS Paramedical (Pharmacy) College, Muradnagar, Ghaziabad, \\ Uttar Pradesh, India, 201206
}

\begin{abstract}
Background and Aim: - Cinnarizine (CNZ) a piperazine derivative with anti-histaminic activity and high affinity to H1 receptors is currently used for the treatment of cerebral arteriosclerosis, cerebral thrombosis, and subarachnoid hemorrhage. The aim of present investigation was to develop a lipid based system i.e. selfmicroemulsifying drug delivery system (SMEDDS) to enhance the oral bioavailability of poorly water soluble CNZ.

Materials and Methods: - The solubility of CNZ in various oils was determined to identify the oil phase for the preparation of SMEDDS. Various surfactants and co-surfactants were screened for their ability to emulsify the selected oil. A Pseudo-ternary phase diagrams were constructed at ambient temperature to identify the efficient self-microemulsifying region using a water titration method. The prepared formulations of SMEDDS were evaluated for their Robustness to dilution, emulsification time, drug loading efficiency, phase separation, droplet size, zeta potential, TEM etc.

Result: - The optimized SMEDDS formulation contained CNZ (25mg), Oleic acid (16.66\%w/w), Tween 80 (55.55\%w/w), Transcutol P $(27.77 \%$ w/w). The optimized formulation of the CNZ loaded SMEDDS exhibited a complete in vitro release in 5 min as compared with marketed formulation which had a limited dissolution rate.

Conclusion: - These results suggest the potential use of SMEDDS to improve the dissolution and hence oral bioavailability of poorly water soluble CNZ.
\end{abstract}

Keywords-Bioavailability, Cinnarizine, Entrapment efficiency, Pseudoternary phase diagram, Selfmicroemulsifying drug delivery system etc.

\section{INTRODUCTION}

By many estimates up to 40 per cent of new chemical entities $\left(\mathrm{NCE}_{\mathrm{S}}\right)$ discovered by the pharmaceutical industry are poor water solubility, and oral delivery of such drug is frequently associated with low bioavailability [1]. These drugs are classified as class II drug by biopharmaceutics classification system (BCS) with poor aqueous solubility and high permeability [2]. For successful oral delivery of such drugs it is imperative to improve the solubility (dissolution rate) these drug candidates. Different approaches for increasing the solubility, and thereby oral absorption and bioavailability of poorly water soluble drugs include use of surfactants, micronization, complexation with cyclodextrins, nanoparticles solid dispersion and lipid-based formulations [3]. Each and every method for bioavailability enhancement has its own limitations. To overcome these limitations, various other formulation strategies have been adopted. Among them, one formulation strategy is lipid-based formulations.

Recently, much attention has been focused on lipid-based formulations to improve the oral bioavailability of poorly water-soluble drug. Among the lipid-based formulations, one formulation is self- micro emulsifying drug delivery systems (SMEDDS). Self microemulsifying drug delivery systems are a promising technology to improve the rate and extent of absorption of poorly water-soluble drugs [4].

Self micro emulsifying systems are isotropic mixtures of oil, surfactants, cosurfactants that form fine oil in water $(\mathrm{O} / \mathrm{W})$ microemulsion upon mild agitation followed by dilution in aqueous media, such as GT fluids. These formulations spread readily in the GIT, and the digestive motility of the stomach and the intestine provide the agitation necessary for self-emulsification. [5]. Self-microemulsifying drug delivery systems indicate the formulations forming transparent microemulsions with oil droplet size less than $50 \mathrm{~nm}$ [6].

Cinnarizine (CNZ), a piperazine derivative with anti-histaminic activity and high affinity to H1 receptors is currently used for the treatment of cerebral arteriosclerosis, cerebral thrombosis, and subarachnoid hemorrhage. A poorly water-soluble Class II drug, the oral delivery of Cinnarizine is precluded due to variable 
dissolution and low bioavailability. The main objective of the investigation is to develop and evaluate SMEDDS containing cinnarizine to improve its oral bioavailability by increasing the solubility of drug.

\section{MATERIAL AND METHODS}

\subsection{Materials}

Cinnarizine (CNZ) was a generous gift from Glenmark Pharmaceuticals Ltd. (Nashik, India). Solutol HS-15(SHS-15), Cremophore-EL (Cr-EL),Transcutol, Cremophore RH 40(Cr-RH),Akoline-MCM(Ak-MCM), Tween 20 and Tween 80 were purchased from S.D. fine chemicals (Mumbai, India), Ethyl oleate, Oleic acid, Miglyol, ethyl laurate, Isopropyl myristate were used. All the excipients and reagents used were analytical grade.

\subsection{Solubility studies}

The solubility of CNZ in various oils, surfactants and cosurfactants was determined by using shake flask method. An excess amount of $\mathrm{CNZ}$ was added to each vial containing $1 \mathrm{~g}$ of the selected vehicle. After sealing, the mixture was vortexing using a cyclomixer for $10 \mathrm{~min}$ in order to facilitate proper mixing of CNZ with the vehicle. Mixtures were then shaken for $48 \mathrm{~h}$ in a water bath shaker (Remi, Mumbai, India) maintained at room temperature. Mixtures were centrifuged at $5000 \mathrm{rpm}$ for $5 \mathrm{~min}$, followed by filtration. Filtrate was suitably diluted with methanol and CNZ dissolved in various vehicles was quantified by UV spectroscopy (Shimadzu 1800). Solubility study was performed at three times and standard deviation was calculated [10].

\subsection{Screening of surfactants}

The purpose of this study was to screen the emulsification ability of various surfactants was screened [10]. Briefly, $300 \mathrm{mg}$ of surfactant was added to $300 \mathrm{mg}$ of the selected oily phase. The mixture was gently heated at $45-60^{\circ} \mathrm{C}$ for homogenizing the components. The isotropic mixture, $50 \mathrm{mg}$, was accurately weighed and diluted with double distilled water to $50 \mathrm{ml}$ to yield fine emulsion. The resulting emulsions were observed visually for the relative turbidity. The emulsions were allowed to stand for $2 \mathrm{~h}$ and their transmittance was assessed by UV double beam spectrophotometer (Shimadzu 1800) using distilled water as blank (Data is shown in Table 1).

\subsection{Screening of co-surfactants}

The turbidimetric method was used to assess relative efficacy of the co-surfactant to improve the nanoemulsification ability of the surfactants and also to select best co-surfactant from the large pool of cosurfactants available [10]. Surfactant $0.2 \mathrm{gm}$ was mixed with $0.1 \mathrm{gm}$ of co-surfactant. Mixture was homogenized with the aid of gentle heat $\left(45-60^{\circ} \mathrm{C}\right)$. The isotropic mixture, $50 \mathrm{mg}$, was accurately weighed and diluted to $50 \mathrm{ml}$ with double distilled water to yield fine emulsion. The emulsions were allowed to stand for $2 \mathrm{hrs}$ and their transmittance was measured by UV-double beam spectrophotometer (Shimadzu 1800) using distilled water as blank (Data is shown in Table 2).

\subsection{Construction of pseudo ternary phase diagrams}

On the basis of the solubility and emulsification study oleic acid, Tween 80 and Transcutol P were selected as oil, surfactants and co-surfactants respectively. To determine the concentration of components for the existing range of the SMEDDS, a pseudoternary diagram was constructed at ambient temperature $\left(25^{\circ} \mathrm{C}\right)$ using a water titration method [12]. Oil, surfactant and co-surfactant were grouped in different combinations for phase studies. Surfactant and co-surfactant $\left(\mathrm{S}_{\text {mix }}\right)$ in each group were mixed in different weight ratio $(1: 0,1: 1$, $1: 2,2: 1,1: 3,3: 1,1: 4,4: 1$ etc). These $S_{\text {mix }}$ ratios were chosen in increasing concentration of surfactant with respect to co-surfactant and in increasing the concentration of co-surfactant with respect to surfactant. For each phase diagram, oil, and specific $S_{\text {mix }}$ ratio are mixed thoroughly in different weight ratio from 1:9 to 9:1 in different glass vials. Different combination of oils, and $S_{\text {mix }}$ were made to those maximum ratios were covered for the study to delineate the boundaries of phase precisely formed in the phase diagrams [13].

\subsection{Evaluation of SMEDDS}

\subsubsection{Robustness to dilution}

Robustness to dilution was studied by diluting the formulation with 100 times volumes of various dissolution media viz. $0.1 \mathrm{~N} \mathrm{HCl}$ and phosphate buffer $(\mathrm{pH} \mathrm{6.8)}$. The diluted microemulsions were stored for 12 $\mathrm{h}$ and observed for any signs of phase separation or drug precipitation [8].

\subsubsection{Globule size analysis}

The globule size of the emulsions was determined by dynamic light scattering (DLS) by monitoring at $25^{\circ} \mathrm{C}$ at a scattering angle $173^{\circ}$ (Zetasizer, Malvern, UK), which measure size range between $6 \mathrm{~nm}$ to $0.6 \mu \mathrm{m}$. The nanometric size range of the particle was retained even after 100 times dilution with water which proves the compatibility of the system with excess water [12].

\subsubsection{Determination of emulsification time}

Self-emulsifying formulations can be graded for self-emulsification time, dispersibility and appearance. Visual assessment criteria for self microemulsion formed from different formulation (Data is shown in Table 3). 


\subsubsection{Zeta Potential}

Zeta potential is used to identify the charge of the droplets. In conventional SMEDDS, the charge on an oil droplet is negative due to presence of free fatty acids [11].Zeta potential determined by Zeta-meter was monitored at $25^{\circ} \mathrm{C}$ at a scattering angle $173^{\circ}$ (Zetasizer Nano-ZS, Malvern, UK).

2.6.5. Transmission electron microscopy

The nanoemulsion globules were visualized by Transmission Electron Microscope (TEM) (MORGAGNI 2680 FEI, (Holland). Samples were dried on carbon-coated grid and negatively stained with aqueous solution of phosphotungstic acid. After drying the specimen was viewed under the microscope.

\subsubsection{Drug loading efficiency:}

$50 \mathrm{mg}$ formulation was taken and to it methanol was added to make up the volume to $100 \mathrm{ml}$. The resultant solution was analysed spectroscopically following suitable dilution. The drug loading efficiency was determined by the following formula

\subsubsection{Stability study}

$$
=\frac{\text { amount of drug in supernatant } \times}{\text { Amount of drug added }} 100
$$

The physical stability study of the various SMEDDS formulations was performed at $4{ }^{\circ} \mathrm{C}, 25^{\circ} \mathrm{C}$ and $45^{\circ} \mathrm{C}$ for 60 days. The SMEDDS was evaluated by visual inspection for physical changes such as color and drug precipitation.

\subsubsection{In vitro dissolution profile}

The quantitative in-vitro drug release from formulation was studied to assess if self emulsifying properties remain consistent. The USP XXIV, dissolution apparatus used to study the release of the drug from the oil in aqueous system. Hard gelatin capsule containing SMEDDS was tied to paddle using para film spring to prevent the capsule from floating $900 \mathrm{ml}$ dissolution media were used standard phosphate buffer solution $\mathrm{pH}$ 6.8. To compare different SMEDDS, dissolution studies were done at $37 \pm 0.5^{\circ} \mathrm{C}$, using paddle rotating at $75 \mathrm{rpm}$, $10 \mathrm{ml}$ sample was withdrawn at 5, 15, 30, 45, $60 \mathrm{~min}$ is that curve reaches a steady state after 15 min., the sample volume of fresh media replaces the withdrawn sample. Sample was filter whatmann filter paper and analysed spectrophotometerically (Shimadzu 1800, Japan) at 250nm. The drug release from the SMEDDS formulation was found to be significantly higher as compared with that of marketed Cinnarizine tablet.

\subsection{Solubility studies}

\section{RESULTS AND DISCUSSION}

Solubility studies were aimed at identifying suitable oily phase and surfactants for the development of CNZ SMEDDS. Identifying the suitable oil, surfactant/co-surfactant having maximal solubilizing potential for drug under investigation is very important to achieve optimum drug loading [3].

The solubility of the drug in various oily phase were screened, oleic acid could solubilize target amount of CNZ $(25 \mathrm{mg})$ at relatively small concentration $90 \mathrm{mg}$. The selection of surfactant or co-surfactant in further study was governed by their emulsification efficiency is shown in Fig 1 \& Fig 2.

\subsection{Screening of surfactants for emulsifying ability}

The \% transmittance values of various dispersions are given in Table 1. Emulsification studies clearly distinguished the ability of various surfactants to emulsify oleic acid. These studies indicated that Tween 80 had very good ability to emulsify oleic acid followed by Cr EL, Cr RH 40, Solutol HS and Tween 20. Although, the HLB values of the surfactants used in the investigation were in the range of 13-16, there was a great difference in their emulsification ability. From these observations concluded that Tween 80 were selected for further investigation.

\subsection{Screening of co-surfactants}

The investigations clearly distinguished the ability of various co-surfactants, both hydrophilic and lipophilic, to improve the emulsification of selected surfactants. Interestingly, all the hydrophilic co-surfactants appeared to be equivalent in improving emulsification ability of Tween 80. In case of lipophilic co-surfactants, good correlation was observed, Transcutol P, lipophilic co-surfactants with good solubilizing potential for CNZ was selected and Tween 80-Transcutol P-Oleic acid systems were developed for further studies.

\subsection{Pseudo-Ternary Phase Diagram}

After the construction of Pseudo ternary phase diagram of $2: 1 \mathrm{~S}_{\operatorname{mix}}$ ratios, maximum area was selected and also which indicate that the area covers the maximum number of formulation. The phase diagram of selected formulation is shown in Fig 3.

\subsection{Preparation of Self Emulsifying Formulation}

After the construction of pseudo ternary phase diagram of $2: 1 \mathrm{~S}_{\operatorname{mix}}$ ratios maximum area covered by particular $S_{\text {mix }}$ was selected and a series of SMEDDs were prepared using oleic acid as the oil, Tween 80 as surfactant and Transcutol $\mathrm{P}$ as the cosurfactant. In all the formulations, the amount of CNZ was kept constant. Accurately weighed CNZ was placed in beaker and oil, surfactant, and co surfactant were added. The 
components were mixed by gentle stirring with magnetic stirrer and the resulting mixture was heated at $40^{\circ} \mathrm{C}$, until the drug was completely dissolved. The homogenous mixture was stored at room temperature until further use. The composition of various selected microemulsion formulations is shown in Table 4.

\subsection{Robustness to dilution}

Robustness to dilution was studied by diluting the system 100 times with various dissolution media viz. $0.1 \mathrm{~N} \mathrm{HCl}$ and phosphate buffer (pH6.8). The diluted microemulsions were stored for $12 \mathrm{~h}$ and it does not indicate any signs of phase separation or drug precipitation (Data is shown in Table 5).

\subsection{Globule size analysis}

The globule size of the emulsions was determined by dynamic light scattering (DLS) by monitoring at $25^{\circ} \mathrm{C}$ at a scattering angle $173^{\circ}$ (Zetasizer Nano-ZS, Malvern, UK), which measure size range between 69.78 $\mathrm{nm}$ to $295.3 \mathrm{~nm}$. The nanometric size range of the particle was retained even after 100 times dilution with water which proves the compatibility of the system with excess water. (Data is shown in Table 6).

\subsection{Determination of emulsification time}

The assessment of time of emulsification showed that with the increase in surfactant concentration the time of emulsification increases. Formulation F-4 , F-5 and F-6 were bluish white and come under grade B, F-7, F-8 and F-9 were appearance to milky and come under grade $\mathrm{C}$ but all other formulation were grade $\mathrm{A}$ and having slightly bluish white appearance (Data is shown in Table 7).

\subsection{Drug loading efficiency}

Drug loading of all the formulations was found to be in between 95.23-97.95\% and statistically it was further justified that there was no significant difference in drug content among the various formulations (Data is shown in Table 8).

\subsection{Stability study}

The stability of CNZ loaded SMEDDS (formulation F 1) was assessed under various storage conditions like room temperature, $30 \pm 2{ }^{\circ} \mathrm{C} / 65 \pm 5 \% \mathrm{RH}, 40 \pm 2 \circ \mathrm{C} / 75 \pm 5 \% \mathrm{RH}$ as per ICH guidelines. SMEDDS equivalent to $25 \mathrm{mg}$ of CNZ was filled hard gelatin capsules and stored at various aforementioned storage conditions for 3 months. Samples were removed at 0, 60, 90 days of interval and checked for CNZ content [14].

\subsection{Zeta Potential Measurement}

The zeta potential indicates the degree of repulsion between adjacent, similarly charged particles in dispersion. For molecules and particles that are small enough, a high zeta potential (positive or negative) will confer stability, that is the solution or dispersion will resist aggregation. When the potential is low, attraction exceeds repulsion and the dispersion will break and flocculate.The value of zeta potential of selected microemulsion formulations F-1 was measured -24.1mv as shown in Fig 7.

\subsection{Transmission Electron Microscopy (TEM) Analysis}

The positive image of optimized formulation (F-1) was observed using TEM as shown in Fig 4. The shape of droplets was found to be spherical. Most of the droplets were of uniform size and shape.

\subsection{In-vitro dissolution study}

Drug release from the SMEDDS formulation (F-1) was found to be significantly higher as compared with that marketed Cinnarizine tablet. It could be suggested that the SMEDDS formulation resulted in spontaneous formation of a microemulsion with a small droplet size, which permitted a faster rate of drug release into the aqueous phase, much faster than that of marketed Cinnarizine tablet. Thus, this greater availability of dissolved Cinnarizine from the SMEDDS formulation could lead to higher absorption and higher oral bioavailability. The maximum drug release was found to be $81.96 \%$ and $87.67 \%$ for F-1 formulation after 5 and 60 min respectively and the results of comparative dissolution study of various formulation is shown in Fig 5.

\section{CONCLUSION}

SMEDDS are vital tool in overcoming the formulation difficulties and improving the oral bioavailability of hydrophobic/lipophilic drugs. In this study, different SMEDDS formulations of Cinnarizine were successfully prepared by simple mixing method and assessed for their in vitro performances. Among various formulations, F-1 formulation showed promising results in the terms of globule size analysis, self emulsification time, zeta-potential, drug loading efficiency and in vitro drug release. Zeta potential of F-1 formulation was $-24.1 \mathrm{mV}$ which indicates good stability and high degree of repulsion between adjacent and similarly charged globules in dispersion. Polydispersity index of formulations F-1 to F-6 were below 0.3 signifying good uniformity in the droplet size distribution after dilution with water. Among the various formulations, F-1 showed highest drug release. It could be concluded that SMEDDS formed from oleic acid, tween 80 and Transcutol $P$ with surfactant co-surfactant ratio (2:1) and Smix-oil ratio (9:1) is a promising approach to improve the solubility, dissolution rate and hence bioavailability of CNZ. The optimized formulation was subjected to stability study as per ICH guidelines and it was found stable under all specified conditions. The optimized formulation showed better drug release as compared to marketed formulation. 


\section{REFERENCES}

[1]. Zhang P, Liu Y. Feng N, Xu J. Preparation and evaluation of self-microemulsifying drug delivery system of oridonin. Int J Pharm 2008; 355:269-27.

[2]. Ghosh PK, Majithiya RJ, Umrethia ML, Murthy RS. Design and development of microemulsion drug delivery system of acyclovir for improvement of oral bioavailability. AAPS Pharm Sci Tech 2006; 7:3-16.

[3]. Humberstone AJ, Charman W. Lipid based vehicles for oral delivery of poorly water soluble drugs. Adv Drug Deliv Rev 2008; 25:103-128.

[4]. Gursoy RN, Benita S. Self-emulsifying drug delivery systems (SEDDS) for improved oral delivery of lipophilic drugs. Biomed Pharmacother 2004; 58: 173-182.

[5]. Pouton C, Porter C. Formulation of lipid-based delivery systems for oral administration: Materials, methods and strategies. Adv Drug Deliv Rev 2008; 60: 625-637.

[6]. Gao P. Enhanced oral bioavailability of a poorly water soluble drug PNU-91325 by supersaturatable formulations. Drug Dev.Ind.Pharm 2004; 30: 221-229.

[7]. Bouchemal K, Brianc S, Perrier E, Fessi H. Nano-emulsion formulation using spontaneous emulsification: solvent, oil and surfactant optimization. Int. J. Pharm 2004; 280: 241-251.

[8]. Patil P, Patil V, Paradkar A. Formulation of self emulsifying system for oral delivery of simvastatin: in vitro and in vivo evaluation. Acta Pharm 2007; 57: 111-122.

[9]. Pouton CW. Lipid formulation for oral administration of drugs: non-emulsifying, self-emulsifying and selfmicroemulsifying drug delivery systems. Eur J Pharm Sci 2000; 11:S93-S98

[10]. Date A, Nagarsenker M.S. Design and evaluation of self nanoemulsified drug delivery systems (SNEDDS) for Cefpodoxime Proxetil. Int. J. Pharm 2007; 329: 166-172.

[11]. Patel RB, Rakesh PP, Patel MM. Self-emulsifying drug delivery systems. Pharm Tech 2008; 1: 1-5.

[12]. Sheikh S, Shakeel F, Talegaonkar S, Ahmad F J, Khar R K, Ali M. Development and bioavailability assessment of ramipril nanoemulsion formulation. Eur J Pharm Biopharm 2007; 66: 227-243.

[13]. Atef E, Belmonte AA. Formulation and in-vitro and in-vivo characterization of a Phenytoin self-emulsifying drug delivery system. Eur J Pharm Sci 2008; 35:257-263.

[14]. Taha E I, Saidam S A, Samy A M, Khan M A. Preparation and in-vitro characterization of a eutectic based semisolid self nanoemulsified drug delivery system of all trans-retinol acetate. Int J Pharm 2004; 285: 247-263.

[15]. Wu W, Wang Y, Que L. Enhanced bioavailability of silymarin by self-microemulsifying drug delivery system. Eur J Pharm Biopharm 2006; 63:288-294.

[16]. Wandel C, Kim R B, Stein M. Inactive excipients such as Cremophor can affect in-vivo drug disposition. Clin Pharm Ther 2003; 73:394-396.

[17]. Yoon K A, Burgess D J. Effect of non-ionic surfactant on transport of model drug in emulsions. Pharm Res 1996; 13:433-439.

[18]. Meinzer A, Mueller E, Vonderscher J. Microemulsion a suitable galenical approach for the absorption enhancement of low soluble compounds. B T Gattefosse 1995; 88:21-26.

[19]. Nazzal S, Smalyukh I I, Lavrentovich O D, Khan M A. Preparation and in-vitro characterization of a eutectic based semisolid self-nanoemulsified drug delivery system (SNEDDS) of ubiquinone: mechanism and progress of emulsion formation. Int J Pharm 2002; 235:247-265.

LIST OF TABLE

Table 1: Emulsification efficiency of various non-ionic surfactants

\begin{tabular}{|l|l|}
\hline Surfactant & \% Transmittance \\
\hline Tween 80 & 99.2 \\
\hline Tween 20 & 94.6 \\
\hline Cr EL & 98.1 \\
\hline Cr RH 40 & 91.5 \\
\hline Solutol HS & 65.6 \\
\hline
\end{tabular}

Table 2: Emulsification studies on surfactants/co-surfactant combinations

\begin{tabular}{|l|l|}
\hline Co-Surfactant & \% Transmittance ( Tween 80) \\
\hline Transcutol P & 91.6 \\
\hline Propylene glycol & 79.3 \\
\hline PEG 400 & 86.4 \\
\hline PEG 300 & 70.8 \\
\hline Ethanol & 76.9 \\
\hline
\end{tabular}


Table 3: Visual assessment criteria for self microemulsification

\begin{tabular}{|l|l|l|}
\hline Grade & $\begin{array}{l}\text { Time required for } \\
\text { microemulsion formation }\end{array}$ & Appearance \\
\hline A & within 1 min. & Clear or slightly bluish \\
\hline B & within 1 min. & bluish white \\
\hline C & within 2 min. & bluish white, similar in appearance to milk \\
\hline D & Longer than $2 \mathrm{~min}$ & Dull, ash emulsion, slightly oily appearance \\
\hline E & Longer than $2 \mathrm{~min}$ & $\begin{array}{l}\text { Poor or minimal emulsification ,large oil } \\
\text { droplets present on the surface }\end{array}$ \\
\hline
\end{tabular}

Table 4: Composition of various selected microemulsion formulations

\begin{tabular}{|l|l|l|l|l|}
\hline Formulations & $\begin{array}{l}\text { Oil } \\
\text { (Oleic acid) } \\
\text { Mg }\end{array}$ & $\begin{array}{l}\text { Surfactant } \\
\text { (Tween80) } \\
\text { Mg }\end{array}$ & $\begin{array}{l}\text { Cosurfactant } \\
\text { (Transcutol }) \\
\text { Mg }\end{array}$ & $\begin{array}{l}\text { Drug } \\
\text { (Cinnarizine) } \\
\text { Mg }\end{array}$ \\
\hline $\begin{array}{l}\text { F 1 } \\
\text { S/CO-(2:1) }\end{array}$ & 90.0 & 300.0 & 150.0 & 25 \\
\hline $\begin{array}{l}\text { F 2 } \\
\text { S/CO-(2:1) }\end{array}$ & 120.0 & 280.0 & 140.0 & 25 \\
\hline $\begin{array}{l}\text { F 3 } \\
\text { S/CO-(2:1) }\end{array}$ & 180.0 & 240.0 & 120.0 & 25 \\
\hline $\begin{array}{l}\text { F 4 } \\
\text { S/CO-(3:1) }\end{array}$ & 92.0 & 336.5 & 112.0 & 25 \\
\hline $\begin{array}{l}\text { F 5 } \\
\text { S/CO-(3:1) }\end{array}$ & 120.0 & 315.0 & 105.0 & 25 \\
\hline $\begin{array}{l}\text { F 6 } \\
\text { S/CO-(3:1) }\end{array}$ & 148.0 & 294.0 & 98.0 & 25 \\
\hline $\begin{array}{l}\text { F 7 } \\
\text { S/CO-(4:1) }\end{array}$ & 90.0 & 360.0 & 90.0 & 25 \\
\hline $\begin{array}{l}\text { F 8 } \\
\text { S/CO-(4:1) }\end{array}$ & 130.0 & 328.0 & 82.0 & 25 \\
\hline $\begin{array}{l}\text { F 9 } \\
\text { S/CO-(4:1) }\end{array}$ & 165.0 & 300.0 & 75.0 & 25 \\
\hline
\end{tabular}

Table 5: Robustness to dilution of various SMEDDS formulation

\begin{tabular}{|c|c|c|c|c|}
\hline Formulation & \multicolumn{2}{|c|}{ Phase Separation } & \multicolumn{2}{|c|}{ Drug Precipitation } \\
\hline & $0.1 \mathrm{~N} \mathrm{HCl}$ & $\begin{array}{l}\text { Phosphate buffer } \\
\text { (pH 6.8) }\end{array}$ & $0.1 \mathrm{~N} \mathrm{HCl}$ & $\begin{array}{c}\text { Phosphate buffer } \\
\text { (pH 6.8) }\end{array}$ \\
\hline F-1 & - & - & -- & -- \\
\hline F-2 & - & - & -- & -- \\
\hline F-3 & - & - & $\cdots$ & 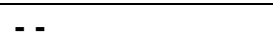 \\
\hline F-4 & - & - & $\cdots$ & 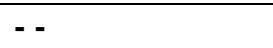 \\
\hline F-5 & - & - & -- & -- \\
\hline F-6 & - & - & -- & -- \\
\hline F-7 & - & - & -- & $\because$ \\
\hline F-8 & - & - & -- & -- \\
\hline F-9 & - & - & -- & -- \\
\hline
\end{tabular}

(+ Phase separation, ++ Drug Precipitation, - No phase separation, - - No precipitation) 
Table 6: Globule size, polydispersity index of various SMEDDS formulations (mean \pm SD, $n=3$ )

\begin{tabular}{|l|l|l|}
\hline Formulation & $\begin{array}{l}\text { Average Globule size } \\
(\mathbf{n m})\end{array}$ & $\begin{array}{l}\text { Polydispersity } \\
\text { Index }\end{array}$ \\
\hline F-1 & $69.78 \mathrm{~nm}$ & 0.183 \\
\hline F-2 & $80.60 \mathrm{~nm}$ & 0.171 \\
\hline F-3 & $101.0 \mathrm{~nm}$ & 0.194 \\
\hline F-4 & $92.67 \mathrm{~nm}$ & 0.319 \\
\hline F-5 & $156.5 \mathrm{~nm}$ & 0.252 \\
\hline F-6 & $169.3 \mathrm{~nm}$ & 0.261 \\
\hline F-7 & $89.58 \mathrm{~nm}$ & 0.493 \\
\hline F-8 & $140.6 \mathrm{~nm}$ & 0.404 \\
\hline F-9 & $295.3 \mathrm{~nm}$ & 0.426 \\
\hline
\end{tabular}

Table 7: Visual assessment of various SMEDDS formulations

\begin{tabular}{|l|l|l|}
\hline Formulation & $\begin{array}{l}\text { Grade based on visual } \\
\text { Observation }\end{array}$ & $\begin{array}{l}\text { Time of emulsification in } \\
\text { Sec) }\end{array}$ \\
\hline F-1 & A & $00: 41$ \\
\hline F-2 & A & $00: 46$ \\
\hline F-3 & A & $00: 49$ \\
\hline F-4 & B & $00: 51$ \\
\hline F-5 & B & $00: 55$ \\
\hline F-6 & B & $00: 58$ \\
\hline F-7 & C & $01: 10$ \\
\hline F-8 & C & $01: 45$ \\
\hline F-9 & C & $01: 56$ \\
\hline
\end{tabular}

Table 8: Drug loading of various SMEDDS formulation

\begin{tabular}{|l|l|}
\hline Formulation & \% Drug loading \\
\hline F-1 & 97.95 \\
\hline F-2 & 96.42 \\
\hline F-3 & 97.73 \\
\hline F-4 & 96.97 \\
\hline F-5 & 97.40 \\
\hline F-6 & 95.99 \\
\hline F-7 & 96.02 \\
\hline F-8 & 96.21 \\
\hline F-9 & 95.23 \\
\hline
\end{tabular}

\section{LIST OF FIGURES}

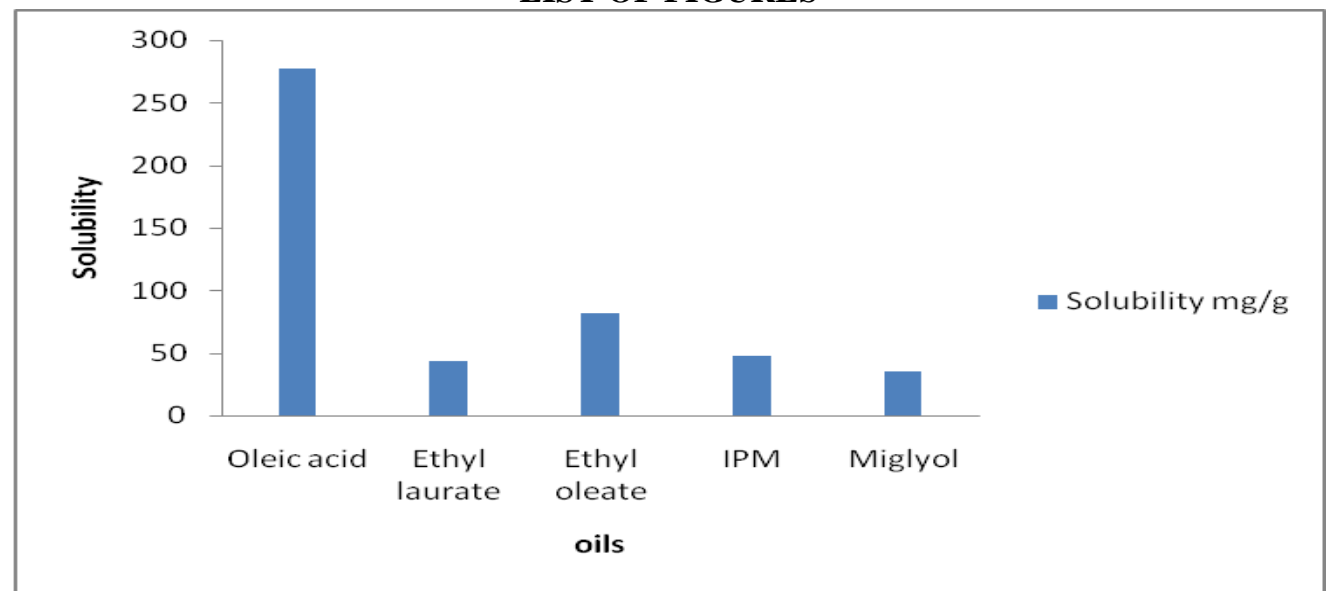

Figure 1: Solubility studies of drug in different oils 


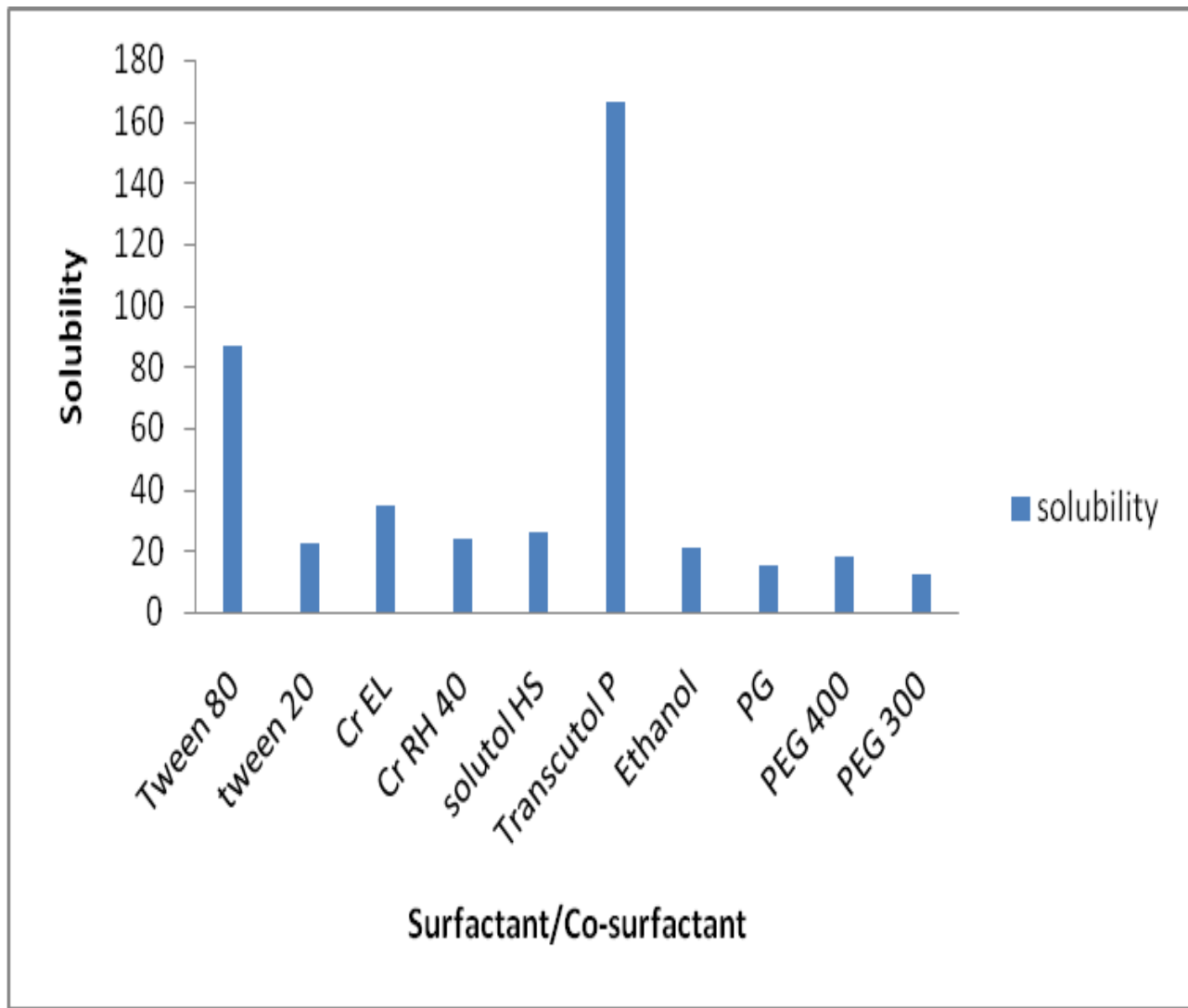

Figure 2: Solubility studies of drug in different surfactants and co-surfactants

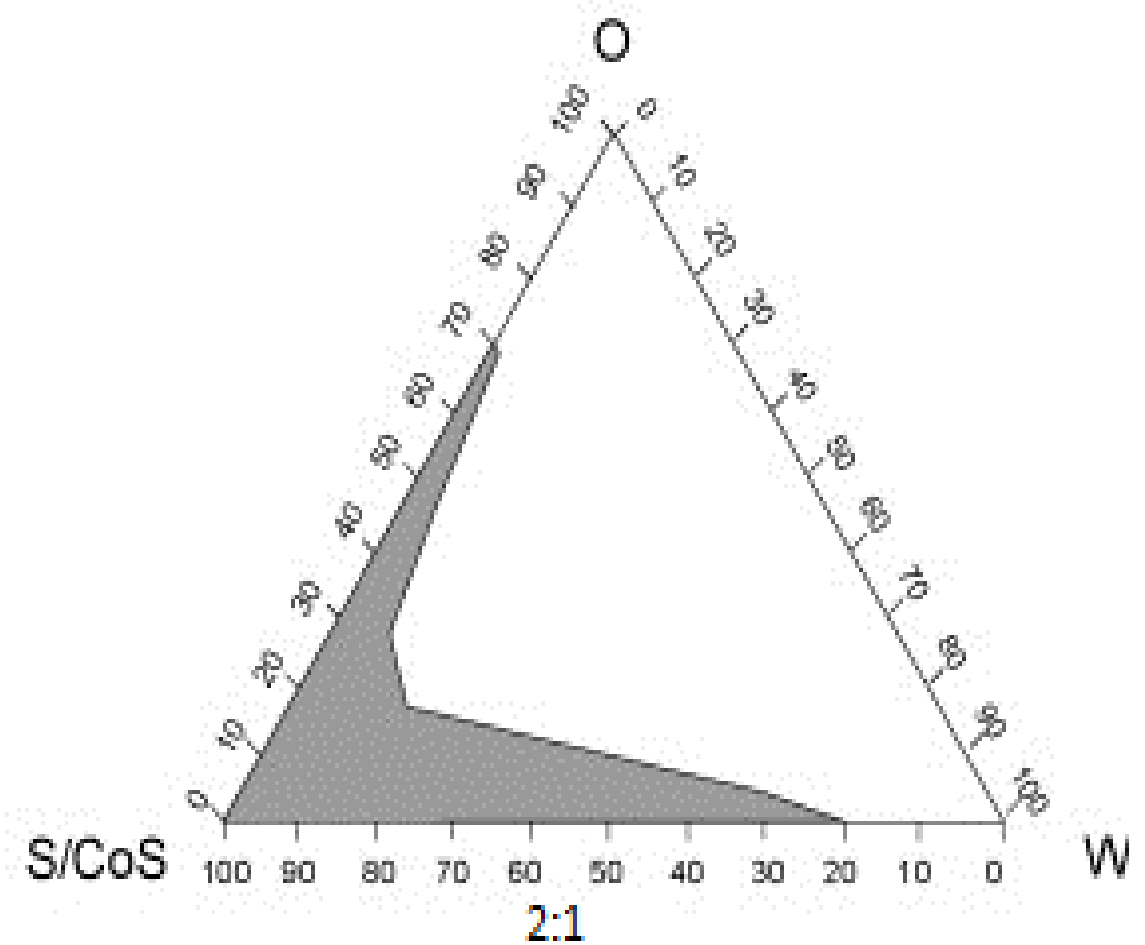

Figure 3: Pseudo ternary phase diagram of Smix ratio 


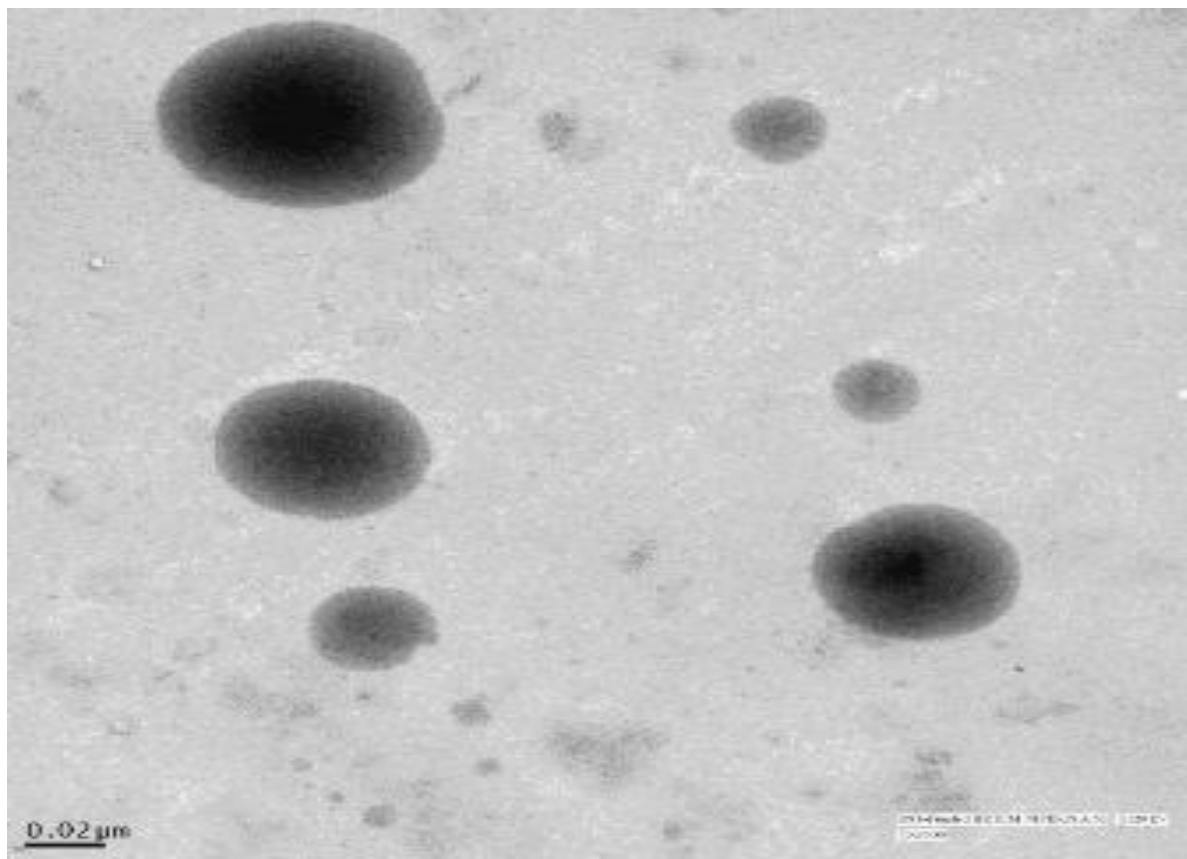

Figure 4: Transmission Electron Microscope positive image of Cinnarizine Micro emulsion of optimized formulation F-1

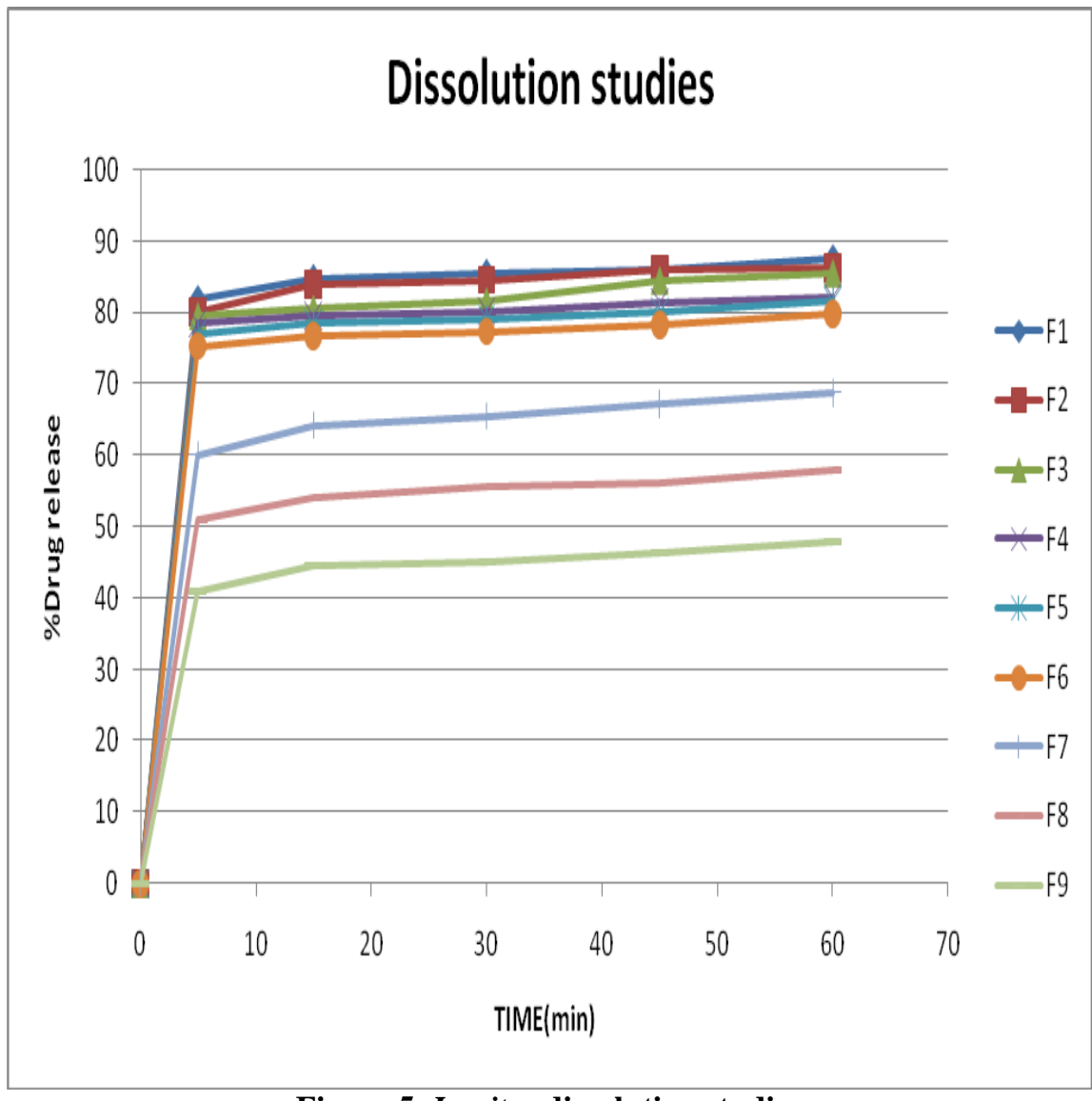

Figure 5: In-vitro dissolution studies 
Results

$\begin{array}{rllll} & & \text { Diam. }(\mathrm{nm}) & \text { \% Intensity } & \text { Width }(\mathrm{nm}) \\ \text { Z-Average (d.nm): } 69.78 & \text { Peak 1: } & 16.82 & 81.8 & 3.716 \\ \text { Pdl: } 0.183 & \text { Peak 2: } & 233.2 & 18.2 & 49.54 \\ \text { Intercept: } 0.968 & \text { Peak 3: } & 0.000 & 0.0 & 0.000\end{array}$

Result quality : Refer to quality report

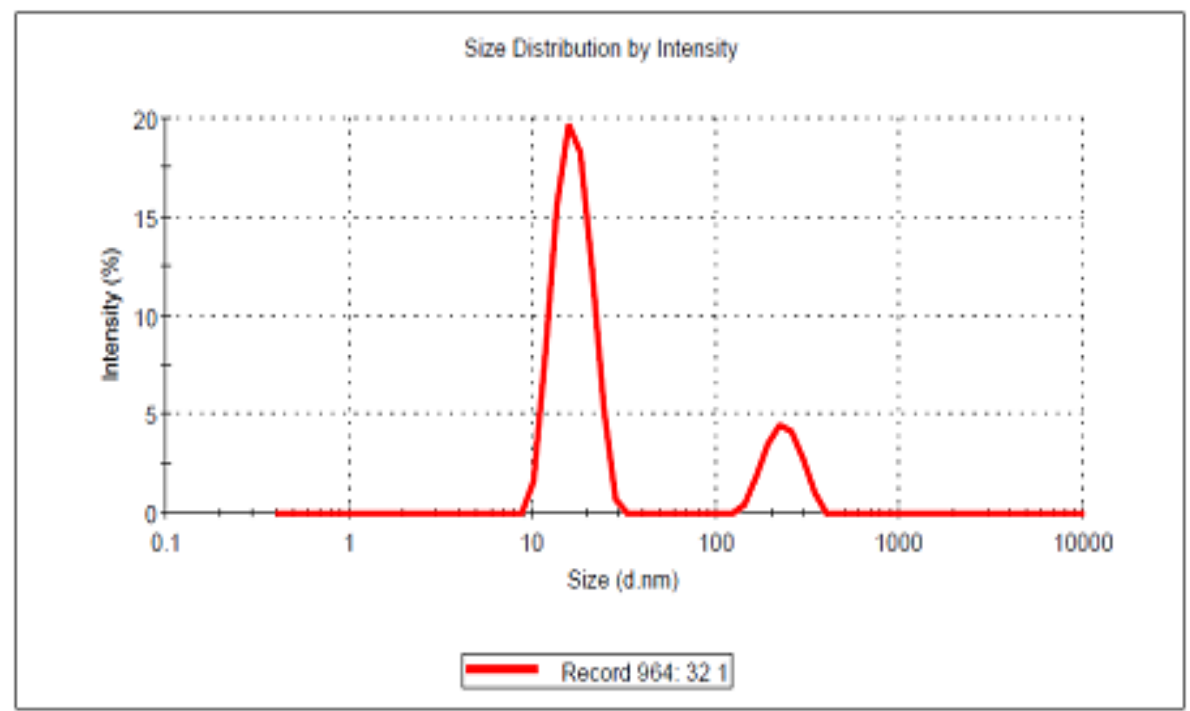

Figure 6: Droplet size analysis of F-1 formulation

Results

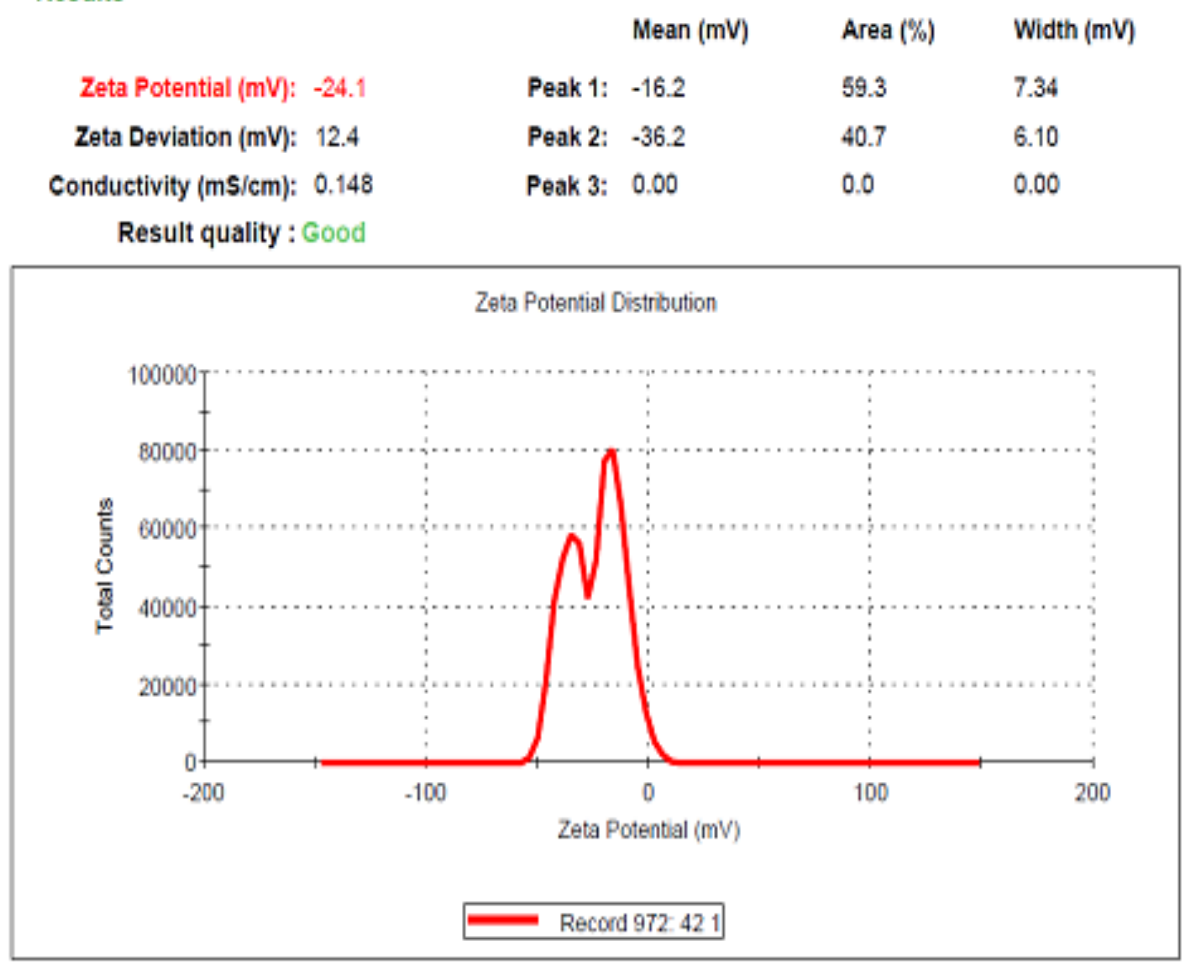

Figure 7: Zeta potential of F-1 formulation 